\title{
KESEHATAN IBU NIFAS
}

NURUL ATHIRA

(70200120063)

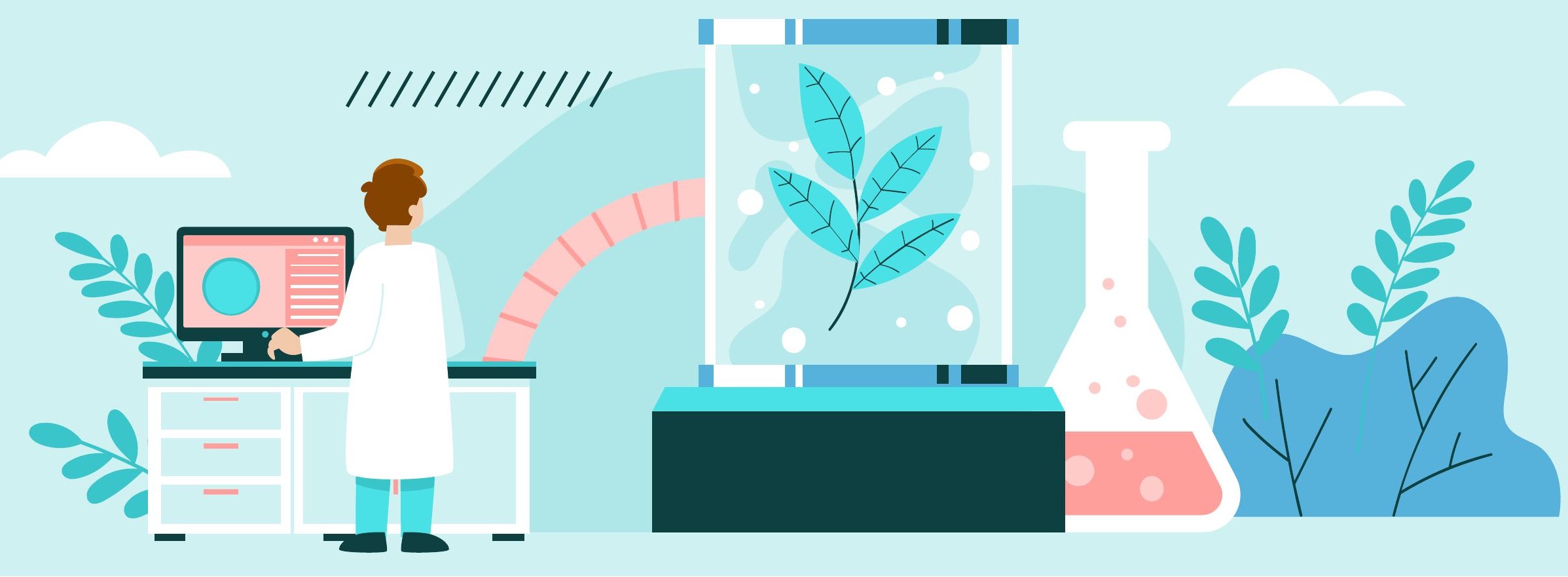




\section{DEFINISI}

Kesehatan reproduksi pada wanita merupakan persoalan tentang seksualitas dan reproduksi yang terkait dengan pelayanan pemeriksaan kehamilan, proses persalinan, dan pengobatan pasca persalinan. Angka kematian ibu dan angka kematian bayi merupakan indikator kesehatan reproduksi di mana di Indonesia masih tinggi dibandingkan dengan negara lainnya (Suryawati, 2007)
Angka kematian ibu dan angka kematian bayi merupakan indikator kesehatan reproduksi di mana di Indonesia masih tinggi dibandingkan dengan negara lainnya

Pada tahun 2013 WHO mencatat hampir 800 (99\%) wanita meninggal setiap hari akibat komplikasi pada masa kehamilan dan persalinan dan terjadi di negara-negara berkembang (WHO, 2014). 


\section{FAKTOR BUDAYA DALAM PERAWATAN IBU NIFAS}

Kepercayaan dan keyakinan budaya terhadap perawatan ibu post partum, masih banyak di jumpai di lingkungan masyarakat.

Mereka meyakini budaya perawatan ibu setelah melahirkan dapat memberikan dampak yang positif dan menguntungkan bagi mereka. Namun, erubahan sosial dan budaya bisa memberikan dampak positif maupun negatif.

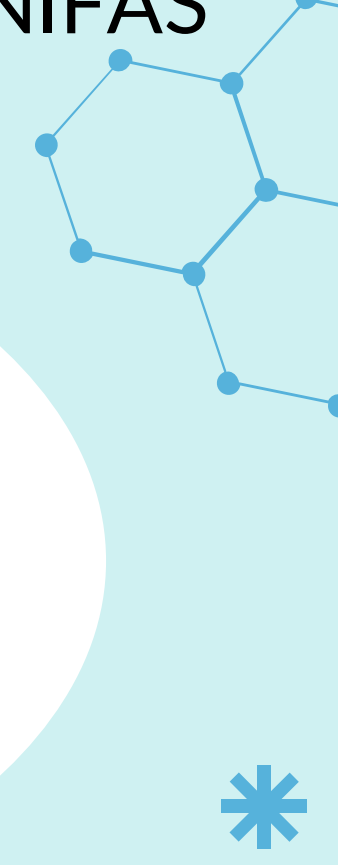




\section{Menurut hasil penelitian Rahayu (2017) ada beberapa pengalaman ibu setelah melahirkan}

Madeung/Sale (Pembakaran) dan Toet Batee (bakar batu)
Kusuk (urut/ pijat), pakai pilis, dan tapel
Pantangan

Makanan

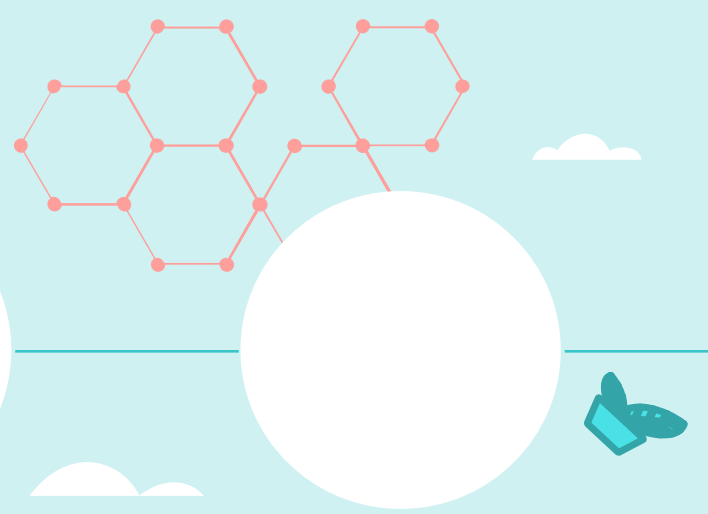

Minum ramu ramuan 
1. Madeung/Sale (Pembakaran) dan Toet Batee (bakar batu)Sale

dilakukan dengan memakai arang panas yang di taruh pada sebuah tungku dan diletakkan di perut.ibu tidur di atas bale yang terbuat dari bambu atau kayu yang di bawahnya dihidupkan api.hal ini bertujuan untuk membersihkan darah kotor, mengembalikan otot dan merampingkan tubuh.
2. Kusuk (urut/ pijat), pakai pilis, dan tapel

Ketidakpuasan dilakukan sejak hari pertama melahirkan dan dilanjutkan selang hari berikutnya. mayoritas menggunakan parem setelah mandi. Pada seluruh bagian tubuh. parem ini di gunakan dengan cara di oleskan ke seluruh tubuh. 


\section{Lanjutan....}

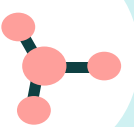

3. Pantangan

Makanan

Ada beberapa dari partisipan mempertahankan untuk melakukan pantang makan, seperti makan telur, sehingga jahitannya menyebabkan terjadi gatalgatal dan dianggap bahwa telur adalah penyebab gatal pada luka jahitan.

\section{Minum}

ramu ramuan

mengkonsumsi jamu. yang ramuannyaberasal dari kunyit. Dengan cara kunyitditumbuk, disaring, kemudian air kunyittersebut di minum setiap pagi juga dibantu dengan makan tape. Manfaatnya dari minum air kunyit adalah apabila masih ada darahkotor belum kering maka akan cepat kering. Juga supaya tidak bau badan.

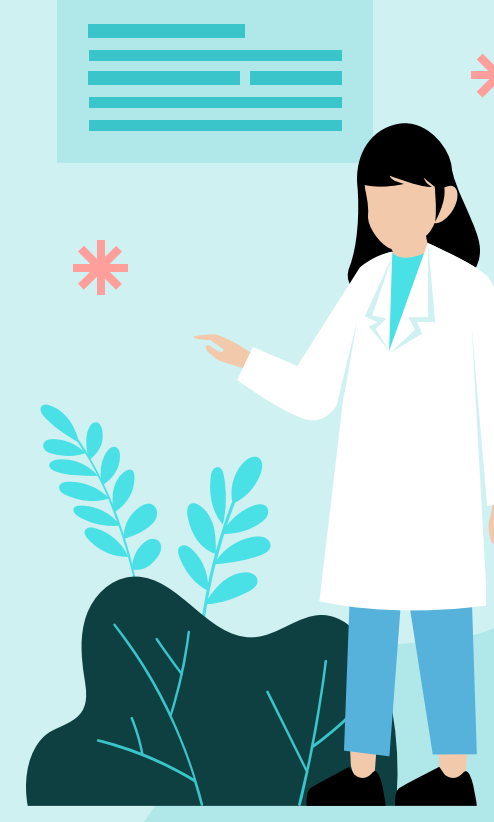


Perbaikan gizi dan hubungan seksual pada umur kehamilan

Infeksi nifas adalah infeksi pada dan melalui traktus genitalis setelah persalinan

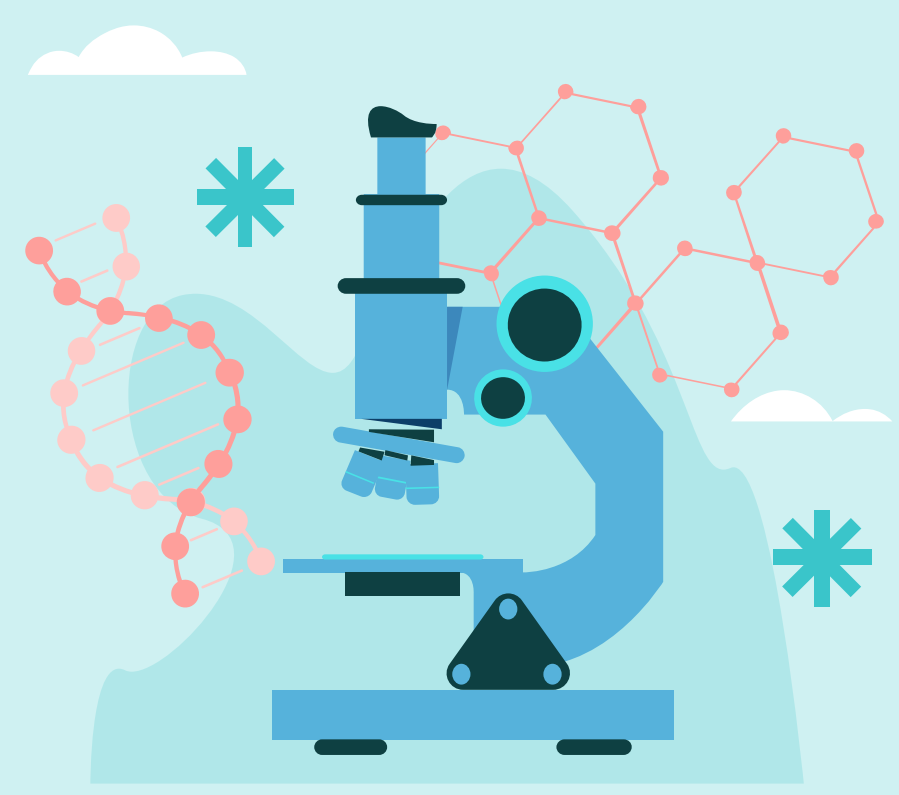
tua sebaiknya tidak dilakukan.

\section{PERSALINAN}

membatasi perlukaan jalan lahir, mencegah perdarahan banyak, menghindari persalinan lama dan menjaga sterilitas ruang bersalin dan alat yang digunakan.

\section{NIFAS}

Perawatan luka post partum dengan teknik aseptic, Semua alat dan kain yang berhubungan dengan daerah genital harus suci hama, Penderita dengan infeksi nifas sebaiknya diisolasi dalam ruangan khusus, tidak bercampur dengan ibu nifas yang sehat. 


\section{$1 / / / / / / / / / \mid$ \\ PEMBERIAN VITAMIN A}

Vitamin A merupakan suplementasi yang diberikan pada ibu menyusui selama masa nifas yang memiliki manfaat penting bagi ibu dan bayi yang disusuinya dengan dosis pemberian $2 \times 200.000 \mathrm{SI}$. 


\section{LANJUTAN.....}

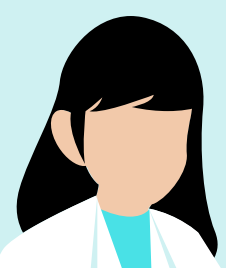

Bagi Bayi Meningkatkan kualitas ASI, Meningkatkan kelangsungan hidup anak dan daya tahan tubuh,

Mencegah komplikasi dari penyakit campak dan diare, Melindungi mata dari xeropthalmia dan buta senja

Bagi Ibu Memelihara kesehatan ibu selama menyusui, Mencegah buta senja karena kurang vitamin $\mathrm{A}$ pemberian yang pertama diberikan segera setelah melahirkan, sedangkan pemberian kedua jarak 24 jam setelah yang pertama dan tidak lebih dari 6 minggu kemudian. 


\section{DAFTAR PUSTAKA}

1. Suryawati, C. (2007). Faktor sosial budaya dalam praktik keperawatan kehamilan, persalinan, dan pasca persalinan. (studi di kecamatan Bangsari, kabupaten Jepara. Diakses pada Jurnal Promosi Kesehatan Indonesia Vol 2

2. WHO. (2014). Media center: maternal mortality, Diakses dari http://www.who.int/gho/maternal.health/en/

3. Rahayu, I. S., Mudatsir, M., \& Hasballah, K. (2017). Faktor budaya dalam perawatan ibu nifas. Jurnal Ilmu Keperawatan, 5(1), 36-49.

4. Khasanah, N. A., \& Sulistyawati, W. (2017). Asuhan Nifas dan Menyusui. E-Book Penerbit STIKes Majapahit, 1-177.

5. E Yulianisa, MS Mardiyah - Jurnal IImiah Kebidanan Indonesia, 2019 journals.stikim.ac.id

6. Janiwarty, B. dan H. Z. Pieter. 2013. Pendidikan Psikologi untuk BidanSuatu Teori dan Terapannya. Rapha Publishing. Yogyakarta. 


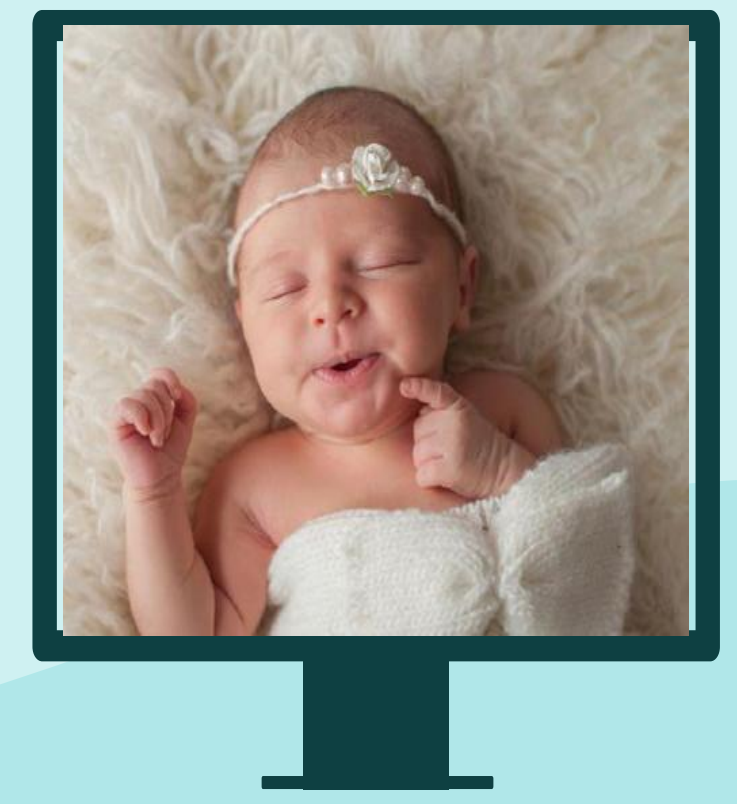

Sembilan bulan mengandung akan menjadi saksi lahirnya anak yang diinginkan dengan tangis, canda dan tawa 
Rahim ibu

Digunting!'Darah Ibu Tumpah! Kepalamu

Ditarik Keluar Melihat Dunia. Ibumu Kesakitan.

Tapi Hadirnya Kamu Adalah Kebahagiaan

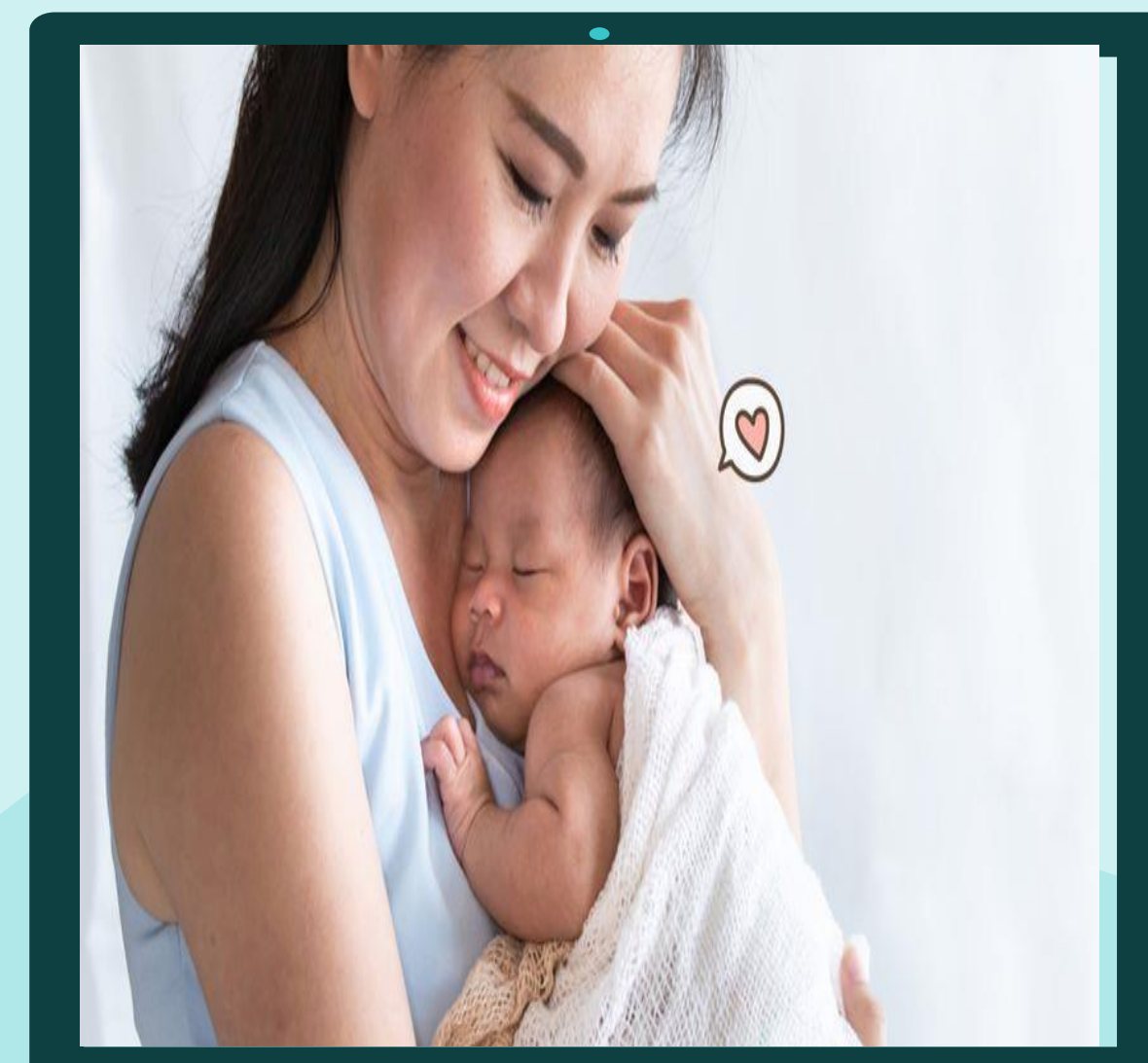


THANK YOU 